\title{
O ENVOLVIMENTO ENTRE FAMÍLIA-ESCOLA DE PRÉ-ESCOLARES COM DEFICIÊNCIA, DIFICULDADES ESCOLARES E DESENVOLVIMENTO TÍPICO ${ }^{1}$
}

\author{
EL INVOLUCRAMIENTO ENTRE FAMILIA-ESCUELA DE PREESCOLARES CON \\ DISCAPACIDAD, DIFICULTADES ESCOLARES Y DESARROLLO TIIPICO
}
THE ENGAGE BETWEEN FAMIL-SCHOOL OF PRESCHOOL CHILDREN WITH DESABILITIES, SCHOOL DIFFICULTIES AND TYPICAL DEVELOPMENT

\author{
Danielli GUALDA MARINS ${ }^{2}$

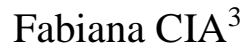

\begin{abstract}
RESUMO: Com o objetivo de comparar e discutir o envolvimento entre família-escola, esse estudo contou com a participação de 87 familiares, nos quais 27 tinham filhos com deficiência, $30 \mathrm{com}$ indicativo de dificuldades escolares e $30 \mathrm{com}$ desenvolvimento típico. Os dados quantitativos foram analisados com métodos descritivos - medidas de tendência central e dispersão -, juntamente com o teste ANOVA para comparar os grupos. Os resultados sugeriram que as pré-escolas que essas crianças frequentavam se relacionavam de maneira diferenciada com cada uma de suas famílias, supondo melhores interações com os que tinham filhos com desenvolvimento típico. Os outros dois grupos demonstraram um envolvimento superficial, especialmente aqueles com indicativo de dificuldades escolares.
\end{abstract}

PALAVRAS-CHAVE: Educação Especial. Educação Infantil. Relação família-escola. Políticas educacionais.

RESUMEN: Con el objetivo de comparar y discutir la relación entre familia-escuela, este estudio contó con la participación de 87 familiares, en los cuales 27 tenían hijos con discapacidad, 30 con indicativo de dificultades escolares y 30 con desarrollo típico. Los datos cuantitativos se analizaron con métodos descriptivos - medidas de tendencia central y dispersión, junto con la prueba ANOVA para comparar los grupos. Los resultados sugirieron que las jardín de infancia que estos niños frecuentaban se relacionaban de manera diferenciada con cada una de sus familias, suponiendo mejores interacciones con los con desarrollo típico. Los otros dos grupos demostraron una implicación superficial, especialmente aquellos con indicativo de dificultades escolares.

PALABRAS CLAVE: Educación Especial. Educación infantil. Relación familia-escuela. Políticas educación.

\footnotetext{
${ }^{1}$ O presente trabalho foi realizado com apoio da Coordenação de Aperfeiçoamento de Pessoal de Nível Superior - Brasil (CAPES) - CAPES/PROEX, nº do Processo: 23038.005155/2017-67.

${ }^{2}$ Universidade Federal de São Carlos (UFSCar), São Carlos - SP - Brasil. Doutoranda no Programa de PósGraduação em Educação Especial, Departamento de Psicologia. ORCID: <https://orcid.org/0000-0002-18280691>. E-mail: dany_gualda@yahoo.com.br

${ }^{3}$ Universidade Federal de São Carlos (UFSCar), São Carlos - SP - Brasil. Docente do Departamento de Psicologia. ORCID: <https://orcid.org/0000-0002-0155-3331>. E-mail: fabianacia@ hotmail.com
} 
ABSTRACT: In aim to compare and discuss family-school involvement, this study had the participation of 87 family members, of wich 27 had children with disabilities, 30 with signs of school difficulties and 30 with typical development. Quantitative data were analyzed using descriptive methods - measures of central tendency and dispersion, along with the ANOVA test to comparison between the groups. The results suggested that the preschools these children attended were related differently to each of their families, assuming the best interactions were were those with typical development. The other two groups showed a superficial engage, especially those with of signs of school difficulties.

KEYWORDS: Special Education. Childhood Education. Family-School relationship. Educational Policy.

\section{Introdução}

Considerando a obrigatoriedade da Educação Infantil para crianças de quatro a cinco anos de idade, as instituições de ensino devem garantir o acesso e a permanência de todos os alunos a partir de seu espaço, tempo, profissionais e recursos pedagógicos (BRASIL, 1996; 2013). Somado a isso, tem sido observado que nos últimos anos as escolas vêm recebendo muitos alunos com diferentes tipos de dificuldades escolares, bem como aqueles que apresentam algum tipo de deficiência.

De tal modo, torna-se urgente discutir essas questões e enfatizar que a reorganização escolar precisa iniciar-se na Educação Infantil, pois além de ser a primeira etapa da Educação Básica, a mesma deve oferecer suporte diante das necessidades de todas as crianças, possibilitando seu total desenvolvimento (MENDES, 2010). Além do artigo 58, do capítulo V da LDBD/96, a Política Nacional de Educação Especial na Perspectiva da Educação Inclusiva (BRASIL, 2008) afirma o princípio da inclusão escolar a partir da população infantil.

Maria-Mengel e Linhares (2007) frisam que para conquistar o maior ganho funcional possível nos primeiros anos de vida, a atenção oferecida às famílias, juntamente com as medidas de reabilitação disponibilizadas às crianças, são primordiais. Ao refletir sobre o ingresso dessas crianças na escola, a Declaração de Salamanca (1994) admite que a proposta inclusiva dentro da Educação Infantil é uma tarefa a ser partilhada entre pais e profissionais.

O Artigo 12 da LDB, no Inciso VI, define como incumbência dos estabelecimentos de ensino "articular-se com as famílias e a comunidade, criando processos de integração da sociedade com a escola". Por sua vez, o Inciso VII mostra que a instituição de ensino tem a obrigatoriedade de enviar informações aos pais ou responsáveis a respeito da frequência e rendimento dos alunos, além da execução da proposta pedagógica da escola (BRASIL, 1996). 
Outro documento que apresentou maior detalhamento referente às formas de articulações entre escolas e famílias foi a Resolução CNE/CEB nº. 5/2009, que instituiu as Diretrizes Curriculares Nacionais para a Educação Infantil, determinando que a organização pedagógica das instituições de Educação Infantil deve assegurar, de acordo com o Artigo 8, “a participação, o diálogo e a escuta cotidiana das famílias, o respeito e a valorização de suas formas de organização". No entanto, Resende e Silva (2016) ressaltam que no contexto brasileiro a relação família-escola encontra-se fracamente regulada, ao compreenderem que as ações baseadas nos textos legais se estabelecem, até o momento, muito dispersas, isoladas e descontínuas, ou seja, há falhas em relação ao detalhamento das formas de realizar tal aproximação.

Além disso, Sigolo (2012) destaca que apesar das mudanças desencadeadas na esfera escolar e familiar, percebe-se ainda a presença do modelo de envolvimento parental tradicional, em que a escola identifica a partir de suas necessidades as ações que aceitam a colaboração e participação da família. Essa autora discute, inclusive, as duas proposições que envolvem a relação família-escola, como a da continuidade embasada no prosseguimento da formação da criança e a da descontinuidade percebida nessas duas instâncias no que diz respeito aos objetivos e procedimentos relacionados às suas próprias finalidades, ou seja, a educação do indivíduo. Essa descontinuidade se mostra extremamente necessária para que realmente a escola desempenhe o papel a ela definido, a transmissão do conhecimento culturalmente produzido. De modo que a família não apresenta a tarefa específica de ensinar o conhecimento formal, apesar dos inúmeros propósitos de educar seus filhos.

Bouchard (1997) enfatiza que, na maioria das vezes, os conhecimentos que a família detém não possui ligação imediata com a ação da escola, pois muitos pais não apresentam condições de acompanhar as atividades escolares dos filhos por conta da cultura previamente estabelecida. Nesse sentido, as representações que os professores têm acerca de uma prática ou procedimento tendem a influenciar nos relacionamentos com os alunos e seus familiares.

De acordo com a heterogeneidade de alunos presente nas escolas, a justificativa do presente estudo se baseia na forma como a criança inicia os primeiros anos escolares, considerando o envolvimento da família com a escola, pois, segundo estudos (CARLOS, 2013; BORGES, 2015; CHRISTOVAM; CIA, 2013; 2016), o mesmo pode refletir significativamente no desempenho acadêmico ao longo das etapas de ensino. Para tanto, o objetivo foi comparar e discutir o envolvimento entre família-escola na opinião de 
pais/responsáveis de pré-escolares com deficiência, dificuldades escolares e desenvolvimento típico.

\section{Método}

\section{Participantes}

Fundamentou-se no critério de amostragem não probabilística por cotas, com a participação de 87 familiares (mãe, pai ou responsável) de pré-escolares, nos quais 27 tinham filhos deficiência (GD), 30 tinham filhos com indicativo de dificuldades escolares (GDA/PC) e 30 tinham filhos com desenvolvimento típico (GDT). Para formação desses grupos, 15 professoras se disponibilizaram em dar informações sobre os aspectos relacionados à aprendizagem e comportamento dessas crianças, por meio do Questionário Capacidades e Dificuldades - SDQ (GOODMAN, 1997, validado por FLEITLICH-BILYK; GOODMAN, 2001), e a parte acadêmica do Social Stills Rating System - SSRS (GRESHAM; ELLIOTT, 1990, adaptado e padronizado por DEL PRETTE; FREITAS; DEL PRETTE, 2016). A criança que tivesse seu comportamento classificado como "limítrofe" ou "clínico" com base nos escores do SDQ e, ainda, apresentasse um rendimento acadêmico abaixo do esperado para sua faixa etária por meio do SSRS, faria parte do GDA/PC. Aquelas que não evidenciaram problemas de comportamento e baixo desempenho acadêmico se encaixaram no GDT.

\section{Procedimento de coleta dos dados}

Após o projeto de pesquisa ser aprovado pelo Comitê de Ética da Universidade Federal de São Carlos (UFSCar) (CAAE: 45108415.9.0000.5504), as professoras e os pais/responsáveis que aceitaram participar da pesquisa assinaram o Termo de Consentimento Livre e Esclarecido e, em seguida, responderam aos instrumentos sob forma de entrevista.

A coleta de dados ocorreu em sete pré-escolas municipais, localizadas em diferentes bairros de um município do estado de São Paulo. Os instrumentos foram aplicados nas dependências das escolas e, em alguns casos, nas residências dos mesmos, sendo que todas as entrevistas foram realizadas de forma individual, em um único dia. Com o grupo de pais/responsáveis de crianças com deficiências (GD), o procedimento de coleta foi igual ao do GDA/PC e GDT, porém considerou-se como critério o fato da criança possuir diagnóstico. 


\section{Medidas avaliativas}

$\mathrm{Na}$ entrevista com os familiares foi utilizado o Questionário Critério Brasil (ABEP, 2015) e o Checklist da rotina compartilhada e envolvimento entre família-escola - versão pai, mãe ou responsável (DESSEN; POLONIA, 2009). Uma das finalidades do Checklist é investigar as dimensões acadêmicas, isto é, as atividades diretamente relacionadas ao desempenho e à aprendizagem formal do aluno.

\section{Procedimento de análise dos dados}

Foram obtidos dados quantitativos analisados com métodos descritivos - medidas de tendência central e dispersão (COZBY, 2006). Para comparar os dados quantitativos entre o GD, GDA/PC e GDT foi utilizado o teste ANOVA.

\section{Resultados e discussões}

A Tabela 1 compara a porcentagem da rotina compartilhada e o envolvimento entre família-escola na dimensão pais-professores, entre o GD, GDA/PC e GDT.

Tabela 1 - Porcentagem da rotina compartilhada e envolvimento entre família-escola na dimensão pais-professores (área acadêmica): Comparação do GD, GDA/PC e GDT

\begin{tabular}{|c|c|c|c|c|}
\hline $\begin{array}{c}\text { Dimensão Pais-professores } \\
\text { (área acadêmica) }\end{array}$ & $\begin{array}{c}\text { GD } \\
(\mathrm{N}=\mathbf{2 7})(\%)\end{array}$ & $\begin{array}{c}\text { GDA/PC } \\
(\mathbf{N}=30) \\
(\%) \\
\end{array}$ & $\begin{array}{c}\text { GDT } \\
(\mathrm{N}=30) \\
(\%)\end{array}$ & $\chi^{2}(\mathrm{df})$ \\
\hline $\begin{array}{l}\text { Escreve no caderno do filho ou envia bilhetes } \\
\text { para a professora, identificando as } \\
\text { dificuldades na realização das tarefas } \\
\text { escolares }\end{array}$ & 88,88 & 76,66 & 100,0 & $\begin{array}{l}3,519 *(1) \\
7,925 *(1)\end{array}$ \\
\hline $\begin{array}{l}\text { Procura a professora para saber do } \\
\text { desenvolvimento escolar do filho }\end{array}$ & 74,07 & 76,66 & 93,33 & $\begin{array}{l}3,964 *(1) \\
3,268^{+}(1)\end{array}$ \\
\hline $\begin{array}{l}\text { Pais e professores conversam sobre as } \\
\text { dificuldades que o filho apresenta na escola }\end{array}$ & 59,25 & 53,33 & 43,33 & - \\
\hline $\begin{array}{l}\text { Procura a professora para saber das atividades } \\
\text { ocorridas na semana, na escola }\end{array}$ & 44,44 & 33,33 & 43,33 & - \\
\hline $\begin{array}{l}\text { Recebe orientaçôes da professora para } \\
\text { desenvolver hábitos de estudo com o filho }\end{array}$ & 44,44 & 26,66 & 53,33 & $4,444 *(1)$ \\
\hline $\begin{array}{l}\text { Recebe orientaçôes da professora para } \\
\text { acompanhar o processo de avaliação escolar }\end{array}$ & 40,74 & 13,33 & 23,33 & $5,505 *(1)$ \\
\hline $\begin{array}{l}\text { Pais e professoras conversam sobre o } \\
\text { desempenho das professoras em sala de aula }\end{array}$ & 40,74 & 10,00 & 43,33 & $\begin{array}{r}7,248 * *(1) \\
8,523 *(1)\end{array}$ \\
\hline $\begin{array}{l}\text { Recebe orientações da professora para } \\
\text { realizar acompanhamento dos conteúdos } \\
\text { escolares }\end{array}$ & 33,33 & 20,00 & 13,33 & $3,229^{+}(1)$ \\
\hline $\begin{array}{l}\text { Pais e professoras conversam sobre as } \\
\text { dificuldades da família que afetam o aluno }\end{array}$ & 22,22 & 16,66 & 20,00 & - \\
\hline
\end{tabular}




Pais e professoras trocam ideias sobre os
problemas de aprendizagem da turma do filho

Fonte: Autoria própria.

Nota $=+\mathrm{p}<0,1 ; * \mathrm{p}<0,05 ; * * \mathrm{p}<0,01 ; * * * \mathrm{p}<0,001$

Os pais/responsáveis das crianças com desenvolvimento típico, quando comparados aos que tinham filhos com deficiência, apresentaram uma relação com a escola estatisticamente maior na dimensão pais-professores nos itens: "Escreve no caderno do filho ou envia bilhetes para a professora, identificando as dificuldades na realização das tarefas escolares" $\left(x^{2}(1)=3,519, \mathrm{p}<0,05\right)$, "Procura a professora para saber do desenvolvimento escolar do filho" $\left(x^{2}(1)=3,964, \mathrm{p}<0,05\right)$ e "Participa do conselho de classe" $\left(x^{2}(1)=2,850\right.$, $\mathrm{p}<0,1)$.

Os participantes do GDT apresentaram, inclusive, relações estatisticamente maiores com a escola, ao serem comparados com os participantes do GDA/PC, nos itens: "Escreve no caderno do filho ou envia bilhetes para a professora, identificando as dificuldades na realização das tarefas escolares" $\left(x^{2}(1)=7,925, \mathrm{p}<0,05\right)$, "Procura a professora para saber do desenvolvimento escolar do filho" $\left(x^{2}(1)=3,268, \mathrm{p}<0,1\right)$, "Recebe orientações da professora para desenvolver hábitos de estudo com o filho" $\left(x^{2}(1)=4,444, \mathrm{p}<0,05\right)$, "Conversam sobre o desempenho das professoras em sala de aula" $\left(x^{2}(1)=8,523, \mathrm{p}<0,05\right)$ e "Participa do conselho de classe" $\left(x^{2}(1)=3,158, \mathrm{p}<0,1\right)$.

As famílias que tinham filhos com deficiência apresentaram uma relação estatisticamente maior com as professoras, ao serem comparadas com aquelas que tinham filhos com indicativo de dificuldades escolares, nos itens: "Recebe orientações da professora para acompanhar o processo de avaliação escolar" $\left(x^{2}(1)=5,05\right.$, $\left.p<0,05\right)$ e "Conversa sobre o desempenho das professoras em sala de aula" $\left(x^{2}(1)=7,248, p<0,001\right)$. Observou-se ainda que o GD, quando comparado com o GDT, apresentou uma relação estatisticamente maior no item: "Recebe orientações da professora para realizar acompanhamento dos conteúdos escolares" $\left(x^{2}(1)=3,229, \mathrm{p}<0,1\right)$. A relação pais-professores do GD demonstrou ser mais 
positiva que a do GDA/PC, possivelmente, para tratar de assuntos relacionados às deficiências dessas crianças, já que envolveu troca de informações relacionadas aos conteúdos escolares, à avaliação escolar e à ação da professora dentro da sala de aula.

Diante disso, alguns questionamentos surgiram: “os pais do GDA/PC se envolveram menos na díade pais-professores, em relação aos outros dois grupos, por conta dos baixos índices de aprendizagem e comportamento dos filhos?"; "eles tinham disponibilidade de tempo para procurarem a escola?"; "por que as professoras forneciam mais orientações para o GDT sobre hábitos de estudo com os filhos e menos para o GDA/PC?" e "por que nenhum participante do GD e do GDA/PC era convocado para os conselhos de classe?".

Esses questionamentos indicam que a relação dos participantes do GDA/PC com as professoras se demonstrou mais negativa. Supostamente, a escola pode ter contribuído para esse fato, pois mesmo não apresentando correlação significativa, 53,3\% deles responderam que conversavam com as professoras sobre as dificuldades que os filhos apresentavam na escola, isto é, a instituição escolar talvez estivesse potencializando mais as dificuldades das crianças do que os outros aspectos. Ainda assim, esse foi o grupo em que os entrevistados eram os que mais trabalhavam fora e os que tinham condições socioeconômicas um pouco mais baixas, fatores que podem ter contribuído no tipo de envolvimento com a escola.

A escola tem o dever de disponibilizar à família informações sobre a escolarização da criança, os processos pedagógicos e, inclusive, solicitar sua participação como membro da comunidade educativa e da gestão democrática (BRASIL, 1996). No entanto, Resende e Silva (2016) assinalaram que a dificuldade de colocá-los em prática se dá porque cada instituição escolar cria suas iniciativas de aproximação e gestão, sendo superficiais às atuais demandas familiares. Tal fato pode ainda ser mais acentuado na Educação Infantil, pois as expectativas tanto dos familiares quanto da escola, muitas vezes, são diferenciadas, além das crianças ainda serem muito pequenas e apresentarem diferentes particularidades em seu desenvolvimento, conforme os três grupos investigados.

A Tabela 2 compara a porcentagem da rotina compartilhada e envolvimento entre família-escola na dimensão pais-direção, entre GD, GDA/PC e GDT. 
Tabela 2 - Porcentagem da rotina compartilhada e envolvimento entre família-escola na dimensão pais-direção (área acadêmica): Comparação do GD, GDA/PC e GD

\begin{tabular}{lcccc}
\hline \multicolumn{1}{c}{$\begin{array}{c}\text { Dimensão Pais-direção } \\
\text { (área acadêmica) }\end{array}$} & $\begin{array}{c}\text { GD } \\
(\mathbf{N = 2 7}) \\
(\mathbf{\%})\end{array}$ & $\begin{array}{c}\text { GDA/PC } \\
(\mathbf{N = 3 0}) \\
(\mathbf{\%})\end{array}$ & $\begin{array}{c}\text { GDT } \\
(\mathbf{N = 3 0}) \\
(\mathbf{\%})\end{array}$ & $\boldsymbol{\chi}^{\mathbf{2}(\mathbf{d f})}$ \\
\hline $\begin{array}{l}\text { Procura a equipe da direção para falar de } \\
\text { assuntos da aprendizagem do filho }\end{array}$ & 48,14 & 16,66 & 03,33 & $\begin{array}{c}6,518^{*}(1) \\
15,403^{* * *}(1) \\
2,963^{+}(1)\end{array}$ \\
\hline $\begin{array}{l}\text { Está envolvido em algum projeto desenvolvido } \\
\text { na escola }\end{array}$ & 00 & 00 & 00 & - \\
\hline
\end{tabular}

Fonte: Autoria própria.

Nota $=+p<0,1 ; * p<0,05 ; * * p<0,01 ; * * * p<0,001$.

$\mathrm{Na}$ dimensão pais-direção, os participantes do GD apresentaram uma relação estatisticamente maior quando comparados aos do GDA/PC $\left(x^{2}(1)=6,518, \mathrm{p}<0,05\right)$ e, também, aos do GDT $\left(x^{2}(1)=15,403, \mathrm{p}<0,001\right)$, no item: "Procura a equipe da direção para falar de assuntos da aprendizagem do filho". Os participantes do GDA/PC, ao serem comparadas com os do GDT, indicaram uma relação estatisticamente maior nesse mesmo item $\left(x^{2}(1)=2,963^{+}\right.$, $\mathrm{p}<0,1)$.

Nota-se que as famílias que tinham filhos com deficiências e com indicativo de dificuldades escolares buscavam mais a direção da escola para tratar de assunto da aprendizagem dos mesmos, fato pouco observado entre as famílias de crianças com desenvolvimento típico. Isso pode indicar que a escola era mais exigente com esses pais/responsáveis ou, ainda, que eles próprios eram mais exigentes e acabavam buscando diretamente a direção. Por outro lado, provavelmente, as professoras não sabiam como lidar com determinadas situações e, especificamente, no caso do GDA/PC, a relação entre eles era mais precária, isto é, a díade pais-professores poderia estar desgastada, fazendo com que muitos assuntos fossem encaminhados diretamente à direção escolar.

Sage (1999) salienta que o papel do diretor deve pautar-se em mecanismos facilitadores para promoção de mudanças necessárias dentro do contexto escolar, considerando os vários níveis e relações estabelecidas dentro dele. Suas atribuições são extremamente necessárias para desmistificar o modelo de envolvimento parental tradicional e, inclusive, para que a descontinuidade entre essas duas esferas (escola e família) se concretize de forma eficaz a partir da Educação Infantil. Sendo assim, o favorável envolvimento entre família-escola, bem como o processo de inclusão escolar, deve ser apoiado por uma gestão democrática de qualidade (BRASIL, 1994; 1996). 
O envolvimento dos pais com a escola não beneficia apenas a crianças, pois as instituições que encorajam os familiares a participarem dos assuntos da escolarização de seus filhos tendem a fortalecer a comunidade como um todo. A partir disso, Bee e Boyd (2011, p. 396) indicam que, "[...] comunidades mais fortes, por sua vez - estejam elas em bairros muito pobres ou em subúrbios de classe média - fornecem melhor supervisão e monitoração das crianças em seu meio". As autoras ressaltam ainda que a forma como a criança inicia os primeiros anos escolares reflete, significativamente, ao longo de suas experiências e seu sucesso escolar.

A Tabela 3 compara a porcentagem da rotina compartilhada e envolvimento entre família-escola na dimensão pais-alunos, entre o GD, GDA/PC e GDT.

Tabela 3 - Porcentagem da rotina compartilhada e envolvimento entre família-escola na dimensão pais-alunos (área acadêmica): Comparação do GD, GDA/PC e GD

\begin{tabular}{|c|c|c|c|c|}
\hline $\begin{array}{l}\text { Dimensão Pais-alunos } \\
\text { (área acadêmica) }\end{array}$ & $\begin{array}{c}\text { GD } \\
(\mathrm{N}=27) \\
(\%) \\
\end{array}$ & $\begin{array}{c}\text { GDA/PC } \\
(\mathbf{N}=30) \\
(\%)\end{array}$ & $\begin{array}{c}\text { GDT } \\
(\mathbf{N}=30) \\
(\%) \\
\end{array}$ & $\chi^{2}(\mathbf{d f})$ \\
\hline $\begin{array}{l}\text { Estimula o filho a copiar, ler, escrever ou } \\
\text { produzir materiais independente das tarefas } \\
\text { escolares }\end{array}$ & 92,59 & 90,00 & 96,66 & - \\
\hline $\begin{array}{l}\text { Orienta o filho quando tem dificuldades de } \\
\text { realizar uma tarefa escolar }\end{array}$ & 88,88 & 80,00 & 96,66 & $4,043 *(1)$ \\
\hline $\begin{array}{l}\text { Conversa com o filho sobre os conteúdos } \\
\text { estudados em sala de aula }\end{array}$ & 85,18 & 90,00 & 96,66 & - \\
\hline Lê livros, revistas ou jornais para seu filho & 81,48 & 70,00 & 80,00 & - \\
\hline $\begin{array}{l}\text { Troca ideias com o filho sobre o professor e a } \\
\text { dinâmica da sala de aula }\end{array}$ & 77,77 & 90,00 & 96,66 & $4,707 *(1)$ \\
\hline $\begin{array}{l}\text { Seu filho procura falar do desempenho dele na } \\
\text { escola }\end{array}$ & 70,37 & 73,33 & 93,33 & $5,180 *(1)$ \\
\hline $\begin{array}{l}\text { Acompanha semanalmente as tarefas escolares do } \\
\text { filho }\end{array}$ & 62,96 & 50,00 & 96,66 & $\begin{array}{l}10,365^{* *}(1) \\
16,705^{* * * *(1)}\end{array}$ \\
\hline $\begin{array}{l}\text { Planeja com o filho a agenda (dia e horários) para } \\
\text { estudo }\end{array}$ & 59,25 & 33,33 & 83,33 & $\begin{array}{c}3,850^{+}(1) \\
4,079 *(1) \\
15,429 * * *(1)\end{array}$ \\
\hline $\begin{array}{l}\text { Identifica junto ao filho as dificuldades } \\
\text { apresentadas por ele na realização das tarefas } \\
\text { escolares }\end{array}$ & 51,85 & 60,00 & 76,66 & $3,842 *(1)$ \\
\hline $\begin{array}{l}\text { Solicita ao filho que mostre os trabalhos } \\
\text { produzidos por ele, na sala de aula }\end{array}$ & 48,14 & 56,66 & 86,66 & $\begin{array}{c}9,758 * *(1) \\
6,648 *(1) \\
\end{array}$ \\
\hline
\end{tabular}

Fonte: Autoria própria.

Nota $=+p<0,1 ; * p<0,05 ; * * p<0,01 ; * * * p<0,001$.

A maioria dos familiares dos três grupos, na dimensão pais-alunos, estimulava os filhos em casa com atividades independentes das tarefas escolares. No entanto, o GDT se destacou em relação ao GD com diferenças estatisticamente maiores nos itens: "Troca ideias com o filho sobre o professor e a dinâmica da sala de aula" $\left(x^{2}(1)=4,707, p<0,05\right)$, "Seu filho 
procura falar do desempenho dele na escola" $\left(x^{2}(1)=5,180, p<0,05\right)$, "Acompanha semanalmente as tarefas escolares do filho" $\left(x^{2}(1)=10,365, \mathrm{p}<0,01\right)$, "Planeja com o filho a agenda (dia e horários) para estudo" $\left(x^{2}(1)=4,079, \mathrm{p}<0,05\right)$, "Identifica junto ao filho as dificuldades apresentadas por ele na realização das tarefas escolares" $\left(x^{2}(1)=3,842, p<0,05\right)$, "Solicita ao filho que mostre os trabalhos produzidos por ele, na sala de aula" $\left(x^{2}(1)=9,758\right.$, $\mathrm{p}<0,01)$

No caso das famílias do GD, constatou-se relação estatisticamente maior, quando comparada com as do GDA/PC, no item: "Planeja com o filho a agenda (dia e horários) para estudo" $\left(x^{2}(1)=3,850, \mathrm{p}<0,05\right)$. As crianças com deficiências tinham uma rotina mais organizada por conta de outros atendimentos recebidos e seus pais/responsáveis eram o que menos trabalhavam fora (conforme os dados do Critério Brasil), ao contrário daquelas que tinham indicativo de dificuldades escolares, ou seja, esses fatores podem ter influenciado a diferença entre elas nesse item.

Algumas variáveis que apareceram anteriormente podem se relacionar com esses achados; por exemplo, na díade pais-professores (Tabela 1), foi constatado que os participantes do GDT enviavam mais bilhetes às professoras quando identificavam dificuldades nas tarefas escolares, isto é, as mesmas eram percebidas, inclusive pelas próprias crianças com a supervisão de seus pais. A hora certa para realizarem as atividades de vida diária também pode ter exercido influência sobre o planejamento de uma agenda para o estudo. Por outro lado, os participantes do GD justificaram que seus filhos não costumavam falar sobre o contexto escolar, bem como o que realizavam lá, mas demonstravam por meio de gestos e expressões positivas que gostavam de frequentá-los. O motivo deles acompanharem menos as tarefas escolares do que o GDT, possivelmente, se associou aos atendimentos que essas crianças tinham fora do contexto escolar, ou ainda, pelo fato de que algumas delas não recebiam tarefas para serem realizadas em casa.

Os familiares do GDT apresentaram relações estatisticamente maiores em comparação com os familiares do GDA/PC, nos itens: "Orienta o filho quando o mesmo tinha dificuldade em realizar a tarefa escolar" $\left(x^{2}(1)=4,043, \mathrm{p}<0,05\right)$, "Seu filho procura falar do desempenho dele na escola" $\left(x^{2}(1)=4,320, \mathrm{p}<0,05\right)$, “Acompanha semanalmente as tarefas escolares do filho" $\left(x^{2}(1)=16,705, \mathrm{p}<0,001\right)$, "Planeja com o filho a agenda (dia e horários) para estudo" 
$\left(x^{2}(1)=15,429, \mathrm{p}<0,001\right)$ e "Solicita ao filho que mostre os trabalhos produzidos por ele, na sala de aula" $\left(x^{2}(1)=6,648, \mathrm{p}<0,05\right)$.

A partir da descrição desses dados, novamente articula-se o vínculo empregatício dos pais/responsáveis do GDA/PC com a disponibilidade de tempo para estabelecer interações com a escola, bem como suas condições socioeconômicas. Além disso, as relações desse grupo na díade pais-professores eram mais negativas e, no caso da díade pais-direção, os assuntos eram voltados para os problemas familiares que afetavam a criança. Assim, o mesmo ocorreu na díade pais-alunos, no qual se notou pouca orientação e planejamento nos afazeres escolares (tarefas e agenda de estudo) dos filhos e, consequentemente, eles não se sentiam estimulados para falarem sobre seu desempenho escolar, talvez por serem mais enaltecido, em ambos os contextos, os aspectos que não eram favoráveis - aprendizagem e comportamento.

Para que a família desenvolva padrões de relação que favoreçam o desenvolvimento de seus filhos, ela precisa de ajuda e atenção no sentido de ampliar suas competências e, ainda, para cumprir as tarefas normativas e não normativas dentro dos ambientes que frequenta. Nesse sentido, a instituição de ensino tem o dever de promover total respaldo a elas, de maneira que as integre na comunidade escolar (BRASIL, 1996), bem como valorizem suas formas de organização (BRASIL, 2010), especialmente para aquelas que possuem filhos pequenos com algum tipo de deficiência ou as que cujos filhos estão começando a demonstrar indicativos de dificuldades escolares.

A Tabela 4 compara a porcentagem da rotina compartilhada e o envolvimento entre família-escola na dimensão pais-pais, entre o GD, GDA/PC e GDT.

Tabela 4 - Porcentagem da rotina compartilhada e envolvimento entre família-escola na dimensão pais-pais (área acadêmica): Comparação do GD, GDA/PC e GD

\begin{tabular}{ccccc}
\hline $\begin{array}{c}\text { Dimensão Pais-pais } \\
\text { (área acadêmica) }\end{array}$ & $\begin{array}{c}\text { GD }(\mathbf{N = 2 7}) \\
(\mathbf{\%})\end{array}$ & $\begin{array}{c}\text { GDA/PC } \\
(\mathbf{N = 3 0}) \\
(\mathbf{\%})\end{array}$ & $\begin{array}{c}\text { GDT (N=30) } \\
(\mathbf{\%})\end{array}$ & $\boldsymbol{\chi}^{\mathbf{2}(\mathbf{d f})}$ \\
\hline $\begin{array}{l}\text { Identifica junto com outros pais as necessidades } \\
\text { pedagógicas da escola }\end{array}$ & 22,22 & 13,33 & 16,66 & - \\
\hline
\end{tabular}

Fonte: Autoria própria.

Nota $=+p<0,1 ; * p<0,05 ; * * p<0,01 ; * * * p<0,001$.

Em relação à dimensão pais-pais, os dados mostram que os participantes dos três grupos pouco se envolviam com outros pais para identificarem juntos as necessidades pedagógicas da escola, talvez pelas circunstâncias culturais diferenciadas (SIGOLO, 2012), 
bem como a baixa sensibilidade da instituição em atender aos tipos de apoios e informações que eles demandavam. Apesar disso, mesmo não apresentando correlação significativa, o GD foi o grupo que mais se destacou nesse item $(22,2 \%)$, supostamente, por buscarem melhorias em relação ao processo de inclusão escolar de seus filhos.

Fica evidente que a instituição escolar necessita oferecer orientações mais claras sobre como as famílias podem participar da educação formal de seus filhos, porém muitos profissionais ainda desconhecem o quanto seu papel é essencial para o progresso das crianças, especialmente nos primeiros anos escolares. Alguns estudos, apesar de evidenciarem apenas as famílias de crianças com deficiências, também chegaram a essa conclusão (CARLOS, 2013; BORGES, 2015; CHRISTOVAN; CIA, 2013, 2016).

A Tabela 5 compara a porcentagem da rotina compartilhada e o envolvimento entre família-escola na dimensão pais-professores-direção, entre o GD, GDA/PC e GDT.

Tabela 5 - Porcentagem da rotina compartilhada e envolvimento entre família-escola na dimensão pais-professores-direção (área acadêmica): Comparação do GD, GDA/PC e GD

\begin{tabular}{|c|c|c|c|c|}
\hline $\begin{array}{l}\text { Dimensão Pais-professores-direção } \\
\text { (área acadêmica) }\end{array}$ & $\begin{array}{c}\text { GD } \\
(\mathbf{N}=27) \\
(\%) \\
\end{array}$ & $\begin{array}{c}\text { GDA/PC } \\
(\mathbf{N}=30) \\
(\%) \\
\end{array}$ & $\begin{array}{c}\text { GDT } \\
(\mathrm{N}=30) \\
(\%)\end{array}$ & $\chi^{2}(\mathbf{d f})$ \\
\hline Expressa sua opinião sobre a escola em um conselho de classe & 29,62 & 50,00 & 36,66 & - \\
\hline $\begin{array}{l}\text { Você junto das professoras e da direção realizam levantamentos } \\
\text { de interesses e necessidades da escola }\end{array}$ & 14,81 & 10,00 & 23,33 & - \\
\hline $\begin{array}{l}\text { Encaminha à direção e as professoras sugestões de mudanças nas } \\
\text { atividades da escola (currículo e Projeto Político Pedagógico) }\end{array}$ & 07,40 & 03,33 & 03,33 & - \\
\hline $\begin{array}{l}\text { Você junto das professoras e da direção discutem os modelos } \\
\text { pedagógicos e de avaliações adotados }\end{array}$ & 07,40 & 00 & 03,33 & - \\
\hline
\end{tabular}

Fonte: Autoria própria.

Nota $=+p<0,1 ; * p<0,05 ; * * p<0,01 ; * * * p<0,001$.

Os dados apontam que $50 \%$ das famílias que tinham filhos com indicativo de dificuldades escolares expressavam sua opinião sobre a escola em um conselho de classe, seguidos por 36,6\% das famílias GDT e $29,6 \%$ das famílias do GD. Salienta-se que tanto as famílias do GDA/PC quanto às do GD não participavam do conselho de classe (Tabela 1), portanto as mesmas indicaram que expressavam suas opiniões em reuniões escolares ou quando julgavam necessárias.

Apesar de uma participação não tanto expressiva, eram as famílias que tinham filhos com desenvolvimento típico as que mais realizavam levantamentos de interesses e necessidades da escola em conjunto com a professora e a direção (23,3\%). Supostamente, isso ocorria porque eles já possuíam melhores rotinas compartilhadas nas outras dimensões. 
Constatou-se inclusive, que nenhum participante que tinha filho com indicativo de dificuldades escolares assinalou que discutia junto com as professoras e a direção os modelos pedagógicos e os tipos de avaliações adotadas.

Por fim, a Tabela 6 compara a porcentagem da rotina compartilhada e o envolvimento entre família-escola na dimensão pais-professores-direção-alunos, entre o GD, GDA/PC e GDT.

Tabela 6 - Porcentagem da rotina compartilhada e envolvimento entre família-escola na dimensão pais-professores-direção-alunos (área acadêmica): Comparação do GD, GDA/PC e

GD

\begin{tabular}{lcccc}
\hline \multicolumn{1}{c}{$\begin{array}{c}\text { Dimensão Pais-professores-direção-aluno } \\
\text { (área acadêmica) }\end{array}$} & $\begin{array}{c}\text { GD } \\
(\mathbf{N = 2 7}) \\
(\boldsymbol{\%})\end{array}$ & $\begin{array}{c}\text { GDA/PC } \\
\mathbf{( N = 3 0 )} \\
(\boldsymbol{\%})\end{array}$ & $\begin{array}{c}\text { GDT } \\
(\mathbf{N}=\mathbf{3 0}) \\
(\boldsymbol{\%})\end{array}$ & $\boldsymbol{\chi}^{\mathbf{2}(\mathbf{d f})}$ \\
\hline $\begin{array}{l}\text { Pais, professoras, equipe da direção e alunos avaliam os } \\
\text { processos pedagógicos e a forma de avaliação adotada }\end{array}$ & 11,11 & 00 & 03,33 & $3,519^{+}(1)$ \\
\hline
\end{tabular}

Fonte: Autoria própria.

Nota $=+\mathrm{p}<0,1 ; * \mathrm{p}<0,05 ; * * \mathrm{p}<0,01 ; * * * \mathrm{p}<0,001$.

Ainda que a participação desses pais demonstrou-se baixa, o GD apresentou relação estatisticamente maior que o GDA/PC no envolvimento entre pais, professoras, direção e alunos para avaliação dos processos pedagógicos e a forma de avaliação adotada $\left(x^{2}(1)=3,519^{+}, \mathrm{p}<0,1\right)$. Considerando a Educação Infantil, torna-se complexo envolver os alunos e seus pais nesse item, porém essa diferença talvez possa ser explicada pela necessidade de haver ajustes e adaptações no projeto pedagógico, no currículo desenvolvido na sala de aula ou, ainda, no plano individual, no qual a participação de toda a comunidade escolar é fundamental (BRASIL, 2006).

Nessa amostra, percebe-se que a escola ainda não apresenta uma compreensão sólida e coerente sobre qual é o papel da família no processo de escolarização. Além do mais, os conhecimentos que esses familiares (em especial os do GD e GDA/PC) detêm, provavelmente, não são suficientes para atender todas as disposições informais das instituições escolares que seus filhos frequentam. Conforme ressalta Sigolo (2012), a presença do modelo de envolvimento parental tradicional ainda se faz presente em muitos contextos, inclusive nos anos iniciais da Educação Básica e diante de toda a heterogeneidade de alunos que a frequentam. 


\section{Considerações finais}

Os resultados sugeriram que as instituições escolares nas quais as crianças do GD, GDA/PC e GDT frequentavam se relacionavam de maneira diferenciada com cada uma de suas famílias, supondo que as melhores interações eram com os que tinham filhos com desenvolvimento típico.

Sendo assim, percebe-se que após dez anos da Política Nacional de Educação Especial na Perspectiva da Educação Inclusiva (BRASIL, 2008), os sistemas de ensino absorveram partes de suas diretrizes, pois a participação da família e da comunidade, bem como a articulação intersetorial na implementação das políticas públicas e as ações das pré-escolas, não estavam ocorrendo de maneira efetiva. Observou-se o acesso das crianças com deficiência aos serviços, porém de maneira desarticulada, o que, consequentemente, pode ter gerado as diferentes demandas analisadas nesse grupo, bem como para aquelas com indicativos de dificuldades escolares.

As implicações práticas desse estudo para a área da Educação Especial refletem que intervenções focadas apenas nas crianças podem ser inviáveis, pois todos seus adultos de referência podem alterar favoravelmente seus repertórios comportamentais quando bem orientados. Por conseguinte, são essenciais intervenções focadas na família e na escola, a fim de criar estratégias conjuntas para um envolvimento compartilhado de qualidade entre elas, bem como a orientação e auxílios nas possíveis demandas que possam surgir ao longo do desenvolvimento das crianças como um todo.

Nesse sentido, os dados apontam a urgência de intervenções baseadas em treinamento de habilidades sociais educativas centradas nas famílias do GDA/PC, pois se presume que as dificuldades escolares das crianças desse grupo estejam atreladas a alguns indicadores de risco observados no ambiente familiar, bem como a falta de apoio/abertura da instituição escolar. Ao mesmo tempo, vale enfatizar que formações em exercício seriam fundamentais para o desenvolvimento de uma gestão democrática, visando à participação familiar e o olhar atento para as singularidades das crianças que fazem parte da Educação Infantil, especialmente aquelas com desenvolvimento atípico.

Como limitação, destaca-se o fato de a pesquisa ter sido realizada por meio de relato verbal de apenas um respondente, no caso pai/mãe ou responsável, sobre o envolvimento família-escola. Tal tipo de pesquisa pode incidir em "respostas socialmente aceitas", por parte do respondente, além de não obter a versão da escola sobre esse envolvimento. No entanto, tal viés foi minimizado por meio das análises estatísticas empregadas e pelo alto número de 
participantes. Assim, pesquisas que investiguem as opiniões da comunidade escolar como um todo podem apresentar maior fidedignidade aos dados.

AGRADECIMENTOS: Ao apoio financeiro fornecido pela CAPES.

\section{REFERÊNCIAS}

\section{ASSOCIAÇÃO BRASILEIRA DE EMPRESAS DE PESQUISA. Questionário Critério} Brasil, 2015.

BEE, H; BOYD, D. A criança em desenvolvimento. 12. Edição. Porto Alegre: Artmed, 2011, p. 396.

BOUCHARD, J. M. 'Partenariado: a família, a escola e os serviços para as pessoas com dificuldades'. In: RODRIGUES-LOPES, A. (org.), Problemática da Família: contributo para uma Reflexão sobre a Família na Sociedade Actual. Viseu: Instituto Superior Politécnico de Viseu, 1997, p. 82-104.

BORGES, L. Relação família e escola: programa para profissionais pré-escolares de alunos público alvo da Educação Especial. 2015. 203f. Dissertação de Mestrado, Programa de PósGraduação em Educação Especial, Universidade Federal de São Carlos, São Carlos, São Paulo, 2015.

BRASIL. Declaração de Salamanca e Linha de Ação sobre Necessidades Educativas Especiais. Brasília: Coordenadoria Nacional para Integração da Pessoa Portadora de Deficiência, 1994.

BRASIL. Lei de Diretrizes e Bases da Educação Nacional. Brasília: MEC, 1996.

BRASIL. Educação Infantil - Saberes e práticas da inclusão: Introdução. Brasília: Ministério da Educação, 2006.

BRASIL. Política Nacional de Educação Especial na Perspectiva da Educação Inclusiva. Brasília: MEC/SEESP, 2008.

BRASIL. Ministério da Educação. Conselho Nacional de Educação. Resolução CNE/CEB N $^{\circ}$ 05/2009, de 17 de dezembro de 2009. Fixa as Diretrizes Curriculares Nacionais para a Educação Infantil. Brasília, 2009.

BRASIL. Diretrizes Curriculares Nacionais para a Educação Infantil. Brasília: Ministério da Educação. Secretaria de Educação Básica, 36p. 2010.

BRASIL. Lei N 12.796, de 4 de Abril de 2013. Brasília: Ministério da Educação, 2013.

CARLOS, D. L. Relação família e escola na inclusão pré-escolar na perspectiva de professores. 2013. 70f. Relatório de pesquisa não publicado. 
CHRISTOVAM, A. C. C.; CIA, F. O envolvimento parental na visão de pais e professores de alunos com necessidades educacionais especiais. Revista Brasileira de Educação Especial, Marília, v. 19, n. 4, p. 563-582, 2013.

CHRISTOVAM, A. C. C.; CIA, F. Comportamentos de pais e professores para promoção da relação família e escola de pré-escolares incluídos. Revista Educação Especial, Santa Maria, v. 29, n. 54, p. 133-146, 2016.

COZBY, P.C. Métodos de pesquisa em ciências do comportamento. 2. ed. São Paulo: Editora Atlas, 2006. p. 454.

DESSEN, M. A.; POLONIA, A. C. Checklist da rotina compartilhada e envolvimento entre família-escola: versão para pais (mãe, pai ou responsável). In: WEBER, L.; DESSEN, M. A. (Orgs.). Pesquisando a família: instrumentos para coleta e análise de dados. Curitiba: Juruá Editora - $1^{\mathrm{a}}$ reimpressão, 2009. p. 199-2002.

GOODMAN, R. The Strengths and Difficulties Questionnaire: A research note. Journal of Child Psychology and Psychiatry, v. 38, n. 65, p. 581-586, 1997.

GRESHAM, F. M.; ELLIOTT, S. N. Inventário de Habilidades sociais, problemas de comportamento e competência acadêmica para crianças: SSRS manual de aplicação, Apuração e Interpretação [DEL PRETTE, Z. A. P.; FREITAS, L. C.; BANDEIRA, M.; DEL PRETTE, A. autores da adaptação e padronização brasileira]. São Paulo: Pearson, 2016.

MARIA-MENGEL, M.; LINHARES, M. Fatores de risco para problemas de desenvolvimento infantil. Revista Latino-Americana de Enfermagem, v. 15, n. esp., p. 837842, 2007.

MENDES, E. G. Inclusão marco zero: começando pelas creches. Araraquara, SP: Junqueira \& Marin, 2010.

RESENDE, T. F.; SILVA, G. F. A relação família-escola na legislação educacional brasileira (1988-2014). Ensaio: Avaliação e Políticas Públicas em Educação, Rio de Janeiro, v. 24, n. 90, p. 30-58, 2016.

SAGE, D.D. Estratégias administrativas para o ensino inclusivo. In: STAINBACK, S.; STAINBACK, W. (Orgs.). Inclusão: um guia para educadores (LOPES, M. F. trad. p. 129141). Porto Alegre: Artes Médicas, 1999.

SIGOLO, S. R. R. L. Envolvimento familiar e educação inclusiva uma mútua contribuição? In: MENDES, E. G.; ALMEIDA, M. A. (Orgs). A pesquisa sobre inclusão escola em suas múltiplas dimensões. Marília: ABPEE, 2012, p. 327-359. 


\section{Como referenciar este artigo}

MARINS, Danielli.; CIA, Fabiana. O envolvimento entre família-escola de pré-escolares com deficiência, dificuldades escolares e desenvolvimento típico. Revista Ibero-Americana de Estudos em Educação, Araraquara, v. 14, n. esp. 1, p. 883-899, abr., 2019. E-ISSN: 19825587. DOI: 10.21723/riaee.v14iesp.1.12213

Submetido em: 06/08/2018

Aprovado em: 21/09/2018 